\title{
Bacteraemia Caused by Kytococcus schroeteri in a Pneumonia Patient Jihye Ha ${ }^{1,2}$, Keon-Han Kim², Jung-Ok Kim¹, Jun-Sung Hong ${ }^{3}$, Seok Hoon Jeong ${ }^{1,2 *}$ and Kyungwon Lee ${ }^{1}$ \\ ${ }^{1}$ Department of Laboratory Medicine and Research Institute of Bacterial Resistance, Yonsei University College of Medicine, Seoul, Korea ${ }^{2}$ Department of Laboratory Medicine, Gangnam Severance Hospital, Yonsei University College of Medicine, Seoul, Korea ${ }^{3}$ Brain Korea 21 PLUS Project for Medical Science, Yonsei University, Seoul, Korea
}

\begin{abstract}
The genus Kytococcus are pigmented, non-encapsulated, non-motile, aerobic, catalase-positive, Gram-positive cocci in pairs or tetrads. We report a case of Kytococcus schroeteri isolated from a blood specimen of a patient with pneumonia. The isolate was Gram-variable and difficult to identify using conventional biochemical tests.
\end{abstract}

Keywords: Kytococcus schroeteri; Gram-variable; 16S rDNA sequencing; Bacteraemia

\section{Introduction}

Kytococci are a part of the normal skin microbiota of humans and can cause infections, particularly in patients with prosthetic devices or immunodeficiency. Due to insufficient identification methods and an intrinsic resistance to several $\beta$-lactams, infections due to Kytococci are a challenge to clinical microbiologists and clinicians [1]. Here, we report the first Korean case of bacteraemia due to Kytococcus schroeteri in a patient with pneumonia.

\section{Case Report}

A 55-year-old man was admitted to a tertiary-care hospital in Seoul, Korea, for evaluation of fever and dyspnea. The patient had no history of hypertension or diabetes mellitus. The patient had been living in a sanatorium because of quadriplegia resulting from a cerebral infarction diagnosed at age 20 years. Laboratory tests showed a leukocyte count of $12.89 \times 10^{9} / \mathrm{L}$ (neutrophil $83.6 \%$ ) and a C-reactive protein level of $156.0 \mathrm{mg} / \mathrm{L}$ (normal range, 0.1-6.0 mg/L). A chest X-ray showed a large amount of pleural effusion and marked peribronchovascular markings in the left lung. Percutaneous catheter drainage of the pleural effusion was performed, but the pleural fluid culture did not yield any bacterial growth. The predominant organism of sputum cultures was a-Streptococcus species, which is thought to be part of the normal flora. A blood culture performed the day the patient was admitted showed Gram-positive cocci growth (isolate GNKS01) in an anaerobic blood culture vial, one of six total (three aerobic and three anaerobic).

Subculture of the blood culture fluid yielded small, slightly yellowpigmented, convex, catalase-positive, and non-haemolytic colonies on $5 \%$ sheep blood agar after $24 \mathrm{~h}$ of incubation in $6 \% \mathrm{CO}_{2}$ at $35^{\circ} \mathrm{C}$. Routine Gram staining of the smeared preparation showed Gram-variable cocci in pairs or tetrads (Figure 1). However, the isolate appeared to be Grampositive after shortening the destaining time from 3-4 sec to 1-2 sec. Morphologic evaluation using scanning electron microscopy (FE SEM S-800, Hitachi, Tokyo, Japan) showed spherical cells $(1.0-1.5 \mu \mathrm{m}$ in diameter) in pairs or tetrads (Figure 2).

Biochemical features were tested using the GP identification card with Vitek 2 system (bioMérieux, "Marcy-I’Étoile", France). However, the commercial card failed to identify the organism. Analysis using matrix-assisted laser desorption/ionization mass spectrometry (MALDI Biotyper, Bruker Daltonics, Bremen, Germany) also failed to identify the organism. 16S rDNA gene sequencing was performed with a universal bacteria primer set, 27F (5'- AGA GTT TGA TCC TGG CTC AG-3') and 1541R (5'- AAG GAG GTG ATC CAG CCG CA-3'), using an automatic sequencer (ABI 3730xl, AB, Weiterstadt, Germany), and the partial 16s rDNA sequences of the isolate GNKS01 were

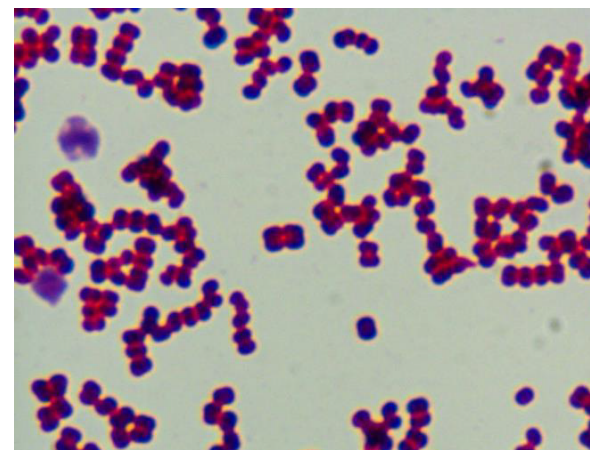

Figure 1: Routine Gram staining of the isolate GNKS01 showed Gramvariable cocci in pairs or tetrads.

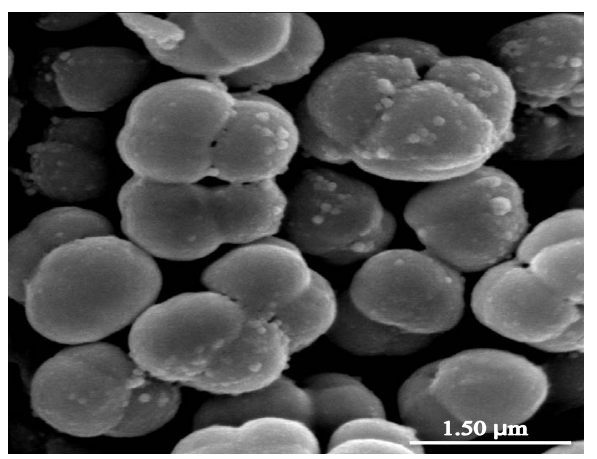

Figure 2: Electron micrograph of $K$. schroeteri isolated from blood specimen. Magnification, 20,000X.

$100 \%$ identical to those of DSM $13884^{\mathrm{T}}$, the type strain of K. schroeteri (GenBank Accesion No. AJ297722.1), according to a BLAST search (http://blast.ncbi.nlm.nig.gov/).

*Corresponding author: Seok Hoon Jeong, Department of Laboratory Medicine and Research Institute of Bacterial Resistance, Yonsei University College of Medicine, 211 Eonju-ro, Gangnam-gu, Seoul 135-720, Korea, Tel: 82-2-2019-3532; E-mail: kscpjsh@yuhs.ac

Received July 14, 2015; Accepted September 17, 2015; Published September 21, 2015

Citation: Ha J, Kim KH, Kim JO, Hong JS, Jeong SH, et al. (2015) Bacteraemia caused by Kytococcus schroeteri in a Pneumonia Patient. J Med Microb Diagn 4 199. doi:10.4172/2161-0703.1000199

Copyright: (c) $2015 \mathrm{Ha} \mathrm{J}$, et al. This is an open-access article distributed under the terms of the Creative Commons Attribution License, which permits unrestricted use, distribution, and reproduction in any medium, provided the original author and source are credited. 
Antimicrobial susceptibility testing was performed with the disk diffusion method. Minimal inhibitory concentrations (MICs) of antimicrobials were determined with Etest strips (bioMérieux) on Mueller-Hinton agar (Asan Pharmaceutical, Seoul, Korea) following the guidelines of the Clinical and Laboratory Standards Institute [2]. The isolate GNKS01 exhibited similar antimicrobial susceptibility patterns to the type strain DSM $13884^{\mathrm{T}}$ (Table 1 ). However, the isolate GNKS01 was susceptible to erythromycin, while the type strain DSM $13884^{\mathrm{T}}$ was resistant.

The patient was treated with tazobactam and ciprofloxacin. He showed good clinical response, and symptoms and elevated inflammatory markers resolved after 10 days.

\section{Discussion}

The genus Kytococcus belongs to the family Dermacoccaceae, which is a part of the suborder Micrococcineae and the order Actinomycetales. The genus Kytococcus was separated from the genus Micrococcus based on phylogenetic (16S rRNA gene sequencing) and chemotaxonomic (menaquinone composition, peptidoglycan types, and cellular fatty acid composition) analysis in 1995 [3]. Kytococci are pigmented, non-encapsulated, non-motile, aerobic, catalase-positive, and Grampositive cocci that appear in pairs or tetrads. The genus consists of three species: Kytococcus sedentarius, Kytococcus aerolatus, and Kytococcus schroeteri. K. sedentarius is a normal saprophyte of the human skin but seldom causes human infections [4]. K. aerolatus was first identified from an indoor air sample and has never been reported to cause human infections [5]. K. schroeteri was first described in 2002, isolated from blood cultures of a patient with prosthetic valve endocarditis and distinguished from $K$. sedentarius based on physiological tests and chemotaxonomic investigations [6]. Though K. schroeteri is a part of the normal human skin flora, it causes systemic human infections associated with prosthetic devices and immunodeficiency. To date, $K$. schroeteri has been identified as a human pathogen in 17 cases; prosthetic valve endocarditis was the most common clinical presentation $(n=8)$ [6-13], followed by pneumonia in immunocompromised patients $(n=5)$ [14-17], ventriculoperitoneal shunt infection $(\mathrm{n}=2)[1,18]$, postoperative spondylodiscitis $(\mathrm{n}=1)$ [19], and implantrelated septic arthritis $(\mathrm{n}=1)$ [20].

\begin{tabular}{|l|c|c|c|c|}
\hline \multirow{2}{*}{ Antimicrobial agent } & \multicolumn{2}{|c|}{ DSM $\mathbf{1 3 8 8 4}$} & \multicolumn{2}{c|}{ GNKS01 } \\
\cline { 2 - 5 } & DDT & $\begin{array}{c}\text { MIC } \\
(\boldsymbol{\mu g} / \mathbf{m l})\end{array}$ & DDT & $\begin{array}{c}\text { MIC } \\
(\boldsymbol{\mu} \mathbf{g} / \mathbf{m l})\end{array}$ \\
\hline Ampicillin & $\mathrm{R}$ & $\mathrm{ND}$ & $\mathrm{R}$ & $\mathrm{ND}$ \\
\hline Penicillin G & $\mathrm{R}$ & $\mathrm{ND}$ & $\mathrm{R}$ & $\mathrm{ND}$ \\
\hline Erythromycin & $\mathrm{R}$ & $\mathrm{ND}$ & $\mathrm{S}$ & $\mathrm{ND}$ \\
\hline Tetracycline & $\mathrm{S}$ & 0.5 & $\mathrm{~S}$ & 0.75 \\
\hline Teicoplanin & $\mathrm{S}$ & $\mathrm{ND}$ & $\mathrm{S}$ & $\mathrm{ND}$ \\
\hline Vancomycin & $\mathrm{S}$ & 0.125 & $\mathrm{~S}$ & 0.094 \\
\hline Linezolid & $\mathrm{S}$ & $\mathrm{ND}$ & $\mathrm{S}$ & $\mathrm{ND}$ \\
\hline Tigecycline & $\mathrm{S}$ & 0.094 & $\mathrm{~S}$ & 0.094 \\
\hline Quinupristin/Dalfopristin & $\mathrm{S}$ & $\mathrm{ND}$ & $\mathrm{S}$ & $\mathrm{ND}$ \\
\hline Tobramycin & $\mathrm{I}$ & $\mathrm{ND}$ & $\mathrm{R}$ & $\mathrm{ND}$ \\
\hline Amikacin & $\mathrm{S}$ & 1.5 & $\mathrm{~S}$ & 1 \\
\hline Trimethoprim/sulfamethoxazole & $\mathrm{S}$ & 0.125 & $\mathrm{~S}$ & 0.125 \\
\hline Ciprofloxacin & $\mathrm{S}$ & 1 & $\mathrm{I}$ & 1 \\
\hline Gentamicin & $\mathrm{S}$ & 0.38 & $\mathrm{~S}$ & 0.5 \\
\hline
\end{tabular}

Abbreviation : DDT, disk diffusion test; MICs, minimal inhibitory concentrations; $\mathrm{S}$ susceptible; I, intermediate; R, resistant; ND, not done

Table 1: Antimicrobial susceptibilities of the type strain DSM $13884^{\top}$ and the $K$. schroeteri clinical isolate from blood culture as determined by the disk diffusion and the Etest.
K. schroeteri is a Gram-positive coccus; however, the isolate GNKS01 showed Gram-variable results in routine Gram staining. A former case report described a similar phenomenon in which identification was hampered because the microorganism was misidentified as Gramnegative cocci [1]. The authors attributed the cause of the abnormal Gram stain reaction to treatment with $\beta$-lactams or the inflamed tissue from which the K. schroeteri was isolated [1]. However, when we performed routine Gram staining for the type strain DSM $13884^{\mathrm{T}}$, we also observed Gram-variable results. Thus, we assume that K. schroeteri may have a property that allows it to be easily destained, which could result in its misinterpretation as Gram-negative cocci.

In this case report, $K$. schroeteri GNKS01 was isolated from a blood specimen of a patient with pneumonia. However, the patient's pleural fluid did not yield any bacterial growth, and the sputum culture did not showed any growth other than $\alpha$-Streptococcus species. Given that the patient did not have any focal infections other than pneumonia, we consider the possibility that his bacteraemia originated from respiratory infection.

In summary, we report a case of $K$. schroeteri bacteraemia successfully treated with tazobactam and ciprofloxacin in a patient with pneumonia. We found that Gram-staining results of $K$. schroeteri can be easily misinterpreted as Gram-negative cocci. Additionally, identification of the Kytococcus spp. isolates using commercially available identification cards and MALDI-TOF MS systems was difficult, indicating the necessity of $16 \mathrm{~S}$ rDNA gene sequencing.

\section{Acknowledgements}

This work was supported by the Research Program funded by the Korea Centers for Disease Control and Prevention (2014E4700200\#).

\section{References}

1. Schaumburg F, Schmalstieg C, Fiedler B, Brentrup A, Omran H, et al. (2013) A bumpy road to the diagnosis of a Kytococcus schroeteri shunt infection. J Med Microbiol 62: 165-168.

2. CaLS I (2011) Performance standards for antimicrobial susceptibility testing: twenty-first informational supplement: CLSI document M100-S21. Clinical and Laboratory Standards Institute, Wayne.

3. Stackebrandt E, Koch C, Gvozdiak O, Schumann P (1995) Taxonomic dissection of the genus Micrococcus: Kocuria gen. nov., Nesterenkonia gen. nov., Kytococcus gen. nov., Dermacoccus gen. nov., and Micrococcus Cohn 1872 gen. emend. Int J Syst Bacteriol 45: 682-692.

4. Levenga H, Donnelly P, Blijlevens N, Verweij P, Shirango H, et al. (2004) Fatal hemorrhagic pneumonia caused by infection due to Kytococcus sedentarius--a pathogen or passenger? Ann Hematol 83: 447-449.

5. Kampfer P, Martin K, Schafer J, Schumann P (2009) Kytococcus aerolatus sp. nov., isolated from indoor air in a room colonized with moulds. Syst Appl Microbiol 32: 301-305.

6. Becker K, Schumann P, Wullenweber J, Schulte M, Weil HP, et al. (2002) Kytococcus schroeteri sp. nov., a novel Gram-positive actinobacterium isolated from a human clinical source. Int J Syst Evol Microbiol 52: 1609-1614.

7. Le Brun C, Bouet J, Gautier P, Avril JL, Gaillot O (2005) Kytococcus schroeteri endocarditis. Emerg Infect Dis 11: 179-180.

8. Mnif B, Boujelbene I, Mahjoubi F, Gdoura R, Trabelsi I, et al. (2006) Endocarditis due to Kytococcus schroeteri: case report and review of the literature. J Clin Microbiol 44: 1187-1189.

9. Renvoise A, Roux V, Casalta JP, Thuny F, Riberi A (2008) Kytococcus schroeteri, a rare agent of endocarditis. Int J Infect Dis 12: 223-227.

10. Aepinus C, Adolph E, von Eiff C, Podbielski A, Petzsch M (2008) Kytococcus schroeteri: a probably underdiagnosed pathogen involved in prosthetic valve endocarditis. Wien Klin Wochenschr 120: 46-49.

11. Poyet R, Martinaud C, Pons F, Brisou P, Carlioz R (2010) Kytococcus schroeteri infectious endocarditis. Med Mal Infect 40: 51-53. 
Citation: Ha J, Kim KH, Kim JO, Hong JS, Jeong SH, et al. (2015) Bacteraemia caused by Kytococcus schroeteri in a Pneumonia Patient. J Med Microb Diagn 4: 199. doi:10.4172/2161-0703.1000199

Page 3 of 3

12. Yousri T, Hawari M, Saad R, Langley S (2010) Kytococcus schroeteri prosthetic valve endocarditis. BMJ Case Rep 2010

13. Liu JC, Jenkins DR, Malnick H, Kovac J, Szostek J (2012) Kytococcus schroeteri endocarditis successfully managed with daptomycin: a case report and review of the literature. J Med Microbiol 61: 750-753.

14. Mohammedi I, Berchiche C, Becker K, Belkhouja K, Robert D, et al. (2005) Fatal Kytococcus schroeteri bacteremic pneumonia. J Infect 51: 11-13.

15. Hodiamont CJ, Huisman C, Spanjaard L, van Ketel RJ (2010) Kytococcus schroeteri pneumonia in two patients with a hematological malignancy. Infection 38: 138-140.

16. Blennow O, Westling K, Froding I, Ozenci V (2012) Pneumonia and bacteremia due to Kytococcus schroeteri. J Clin Microbiol 50: 522-524.
17. Nagler AR, Wanat KA, Bachman MA, Elder D, Edelstein PH, et al. (2011) Fatal Kytococcus schroeteri infection with crusted papules and distinctive histologic plump tetrads. Arch Dermatol 147: 1119-1121.

18. Jourdain S, Miendje Deyi VY, Musampa K, Wauters G, Denis O, et al. (2009) Kytococcus schroeteri infection of a ventriculoperitoneal shunt in a child. Int $J$ Infect Dis 13: 153-155.

19. Jacquier H, Allard A, Richette P, Ea HK, Sanson-Le Pors MJ, et al. (2010) Postoperative spondylodiscitis due to Kytococcus schroeteri in a diabetic woman. J Med Microbiol 59: 127-129.

20. Chan JF, Wong SS, Leung SS, Fan RY, Ngan AH, et al. (2012) First report of chronic implant-related septic arthritis and osteomyelitis due to Kytococcus schroeteri and a review of human $K$. schroeteri infections. Infection 40: 567-573. 